\title{
A tradição como problema nos estudos de comunicação: reflexões a partir de Williams e Ricoeur
}

\author{
Bruno Souza Leal' \\ https://orcid.org/0000-0002-6937-6976 \\ Igor Sacramento" \\ https://orcid.org/0000-0003-1509-4778 \\ I - UFMG \\ Belo Horizonte (MG), Brasil \\ II - Fiocruz \\ Rio de Janeiro (RJ), Brasil
}

Resumo: Neste artigo, buscamos refletir sobre a tradição como um problema a ser enfrentado nos estudos em Comunicação. A partir da retomada de dois importantes pensamentos sobre o tema, nas obras de Raymond Williams e de Paul Ricoeur, explicitamos a dimensão interpretativa e os complexos movimentos temporais presentes na tradição. A retomada desses autores, de filiações e preocupações teóricas bem diversas, não visa buscar conexões entre eles, mas mostrar como ambos, a seu modo, entendem a tradição como algo instável, imersa em conflitos epistêmicos, éticos e ideológicos e encontram, na disputa sobre o passado, a configuração do presente e a projeção de futuros.

Palavras-chave: tradição; Raymond Williams; Paul Ricouer.

Abstract: Tradition as a problem in communication studies: reflections from Williams and Ricoeur - In this study, we aim to reflect on tradition as a problem to be faced in Communication studies. Based on a resumption of two important thoughts on tradition, in the works of Raymond Williams and Paul Riceour, we describe the interpretative dimension and complex temporal movements present in tradition (unpleasant repetition of "tradition". A resumption of these authors, affiliations and quite diverse theoretical concerns are not aimed at seeking connections between them, but to show how both, in their way, understand tradition as something unstable, immersed in epistemic, ethical and ideological conflicts, and in the dispute on the past, the configuration of the present and projection of the future.

Keywords: tradition; Raymond Williams; Paul Ricoeur. 


\section{Introdução}

De modo geral, pode-se dizer que a tradição, nos estudos em Comunicação, ou é frequentemente entendida como um acervo relativamente estável e transmissível que informa e situa numa linha temporal o que se estuda no presente ou não é merecedora de um olhar mais atento. Em direção contrária a esse diagnóstico, este artigo busca apresentar as relações de tradicionalidade como um problema e uma dimensão importante para o estudo de produtos e processos comunicacionais. No esforço de delinear aspectos relevantes, dois autores, de tradições teóricas muito distintas, nos são particularmente instigantes: Raymond Williams, em que se acentua a relação entre tradição, ideologia e cultura, e Paul Ricoeur, em que as dimensões ética e epistemológica ganham mais relevo. Dos dois, a menção a Williams pode parecer mais exógena. Afinal, enquanto o filósofo francês se dedicou, em mais de um momento de sua longa carreira, à reflexão sobre a tradição, o pensador inglês é reconhecido por sua atenção a outras questões-chave, como a cultura, as transformações históricas e a hegemonia.

Ambos autores, porém, apreendem a tradição como parte dos movimentos conflitivos do tempo, no qual se apresentam dimensões ideológicas, culturais, éticas e epistemológicas. Ainda que refletindo com preocupações e filiações teóricas bem específicas, tanto Ricoeur quanto Williams reconhecem e apontam para as conexões entre essas dimensões da tradição, privilegiando umas ou outras na sua trajetória intelectual. Sua importância se acentua especialmente, como se verá, quando se considera que os autores têm fornecido bases e referenciais para o desenvolvimento de trabalhos recentes dedicados à historicidade de fenômenos comunicacionais.

Ao dialogarmos com os dois pensadores, buscamos, conscientes dos desafios impostos, explicitar o quanto a investigação sobre a tradição - como categoria e fenômeno social - é imprescindível para o estudo da historicidade dos processos comunicacionais. Ao nosso olhar, a tradição é um termo fundamental para a apreensão da dimensão temporal nos fenômenos e processos comunicacionais e, para tal, precisa ser apreendida em sua instabilidade e nos movimentos temporais que abriga, à semelhança do que diferentes autores propuseram para a noção de contexto (BARBOSA; REGO, 2017; GOULART; MARTINS; ANTUNES, 2017; LEAL; CARVALHO, 2017; MAIA; SACRAMENTO;VILAS BOAS, 2017, entre outros). A recuperação das reflexões de Raymond Williams e Paul Ricoeur neste artigo não tem nenhuma intenção comparativa ou de encontrar um ponto comum entre eles. Interessanos observar, aí sim, como pensamentos de preocupações e filiações teóricas tão diversas identificaram características e dimensões específicas no seu entendimento da tradição e como estão sendo, aos poucos, incorporadas em estudos de comunicação no Brasil.

\section{A noção de tradição seletiva em Williams}

É exatamente em conexão com a hegemonia, termo caro a uma longa corrente de pensamento marxista, que a noção de tradição surge no pensamento de Williams. 
Em Marxismo e Literatura, publicado em 1977, por exemplo, a palavra tradição é encontrada perto de 60 vezes, em momentos distintos: ora na reflexão sobre a constituição da ideia de uma literatura nacional, ora na revisão de perspectivas e obras caras ao marxismo, ora na caracterização de processos e dinâmicas culturais. Mas é exatamente na reflexão sobre hegemonia, em diálogo claro com o pensamento gramsciano, que a noção de tradição significativamente começa a ser sistematizada, algo que ganha corpo no tópico seguinte, intitulado Tradições, instituições e formações.

Em Williams, a tradição adquire contornos interessantes e precisos. Ela é plural, integra as dinâmicas de poder e conflitos sociais e, menos que "um segmento inerte, historicizado, de uma estrutura social", precisa ser entendida como uma "força ativamente modeladora" (WILLIAMS, 1979, p.118). No singular, qualquer tradição é necessariamente seletiva, à medida que, no ritmo de disputas de valores e poderes, atua para ratificar e legitimar uma dada construção hegemônica atual. Daí decorre que a tradição, menos do que um acervo de heranças que chegam do passado, é "um aspecto da organização social e cultural contemporânea, no interesse do domínio de uma classe específica. É uma versão do passado que se deve ligar ao presente e ratificá-lo. O que oferece, na prática, é um senso de continuidade predisposta" (WILLIAMS, 1979, p.119).

Quando articula a tradição seletiva à continuidade predisposta de uma dada configuração cultural hegemônica, Williams não apenas reconhece que é ela uma construção do presente sobre o passado como deixa claro suas consequências na projeção de futuros. Inserida nos processos e dinâmicas dos conflitos sociais, uma dada tradição emerge como uma espécie de ferramenta de uma ordem hegemônica no intuito de se legitimar na construção de um passado adequado ou pressuposto e na projeção de um futuro em conformidade com essa configuração contemporânea.

Exatamente porque é seletiva e imersa em relações de poder, que uma tradição é inevitável e simultaneamente poderosa e vulnerável. Afinal, lembra Williams, a emergência de uma tradição põe de lado, dilui, reinterpreta e/ou faz convergir, sem aparente contradição, áreas inteiras de significação histórico-social. Com isso, abre espaço para ações interpretativas contra-hegemônicas e alternativas, exatamente na retomada do que é esquecido ou esvaziado. Nesse momento, os conflitos - ideológicos - das tradições, sob o olhar de Williams (1979), encarnam-se fortemente às práticas cotidianas, reforçando a premissa da tradição como um fenômeno histórico e, portanto, dinâmico.

Longe de ser somente uma espécie de monumento de veneração e culto, a tradição comporta em seu interior movimentos ideológicos e políticos decisivos para as conexões que estabelece entre fatos, produtos e épocas. Ao mesmo tempo, uma vez que responde a configurações de poder contemporâneas, uma tradição está inserida numa correlação de forças, de hegemonia e contra-hegemonia, de legitimação e deslegitimação, ou seja, é parte significativa (como objeto e como agente) nos fluxos ideológicos e culturais de um dado momento. Para Williams (1979, p.113), a hegemonia é "todo um conjunto de práticas 
e expectativas, sobre a totalidade da vida: nossos sentidos e distribuição de energia, nossa percepção de nós mesmos e nosso mundo. É um sistema vivido de significados e valores - constitutivo e constituidor - que, ao serem experimentados como práticas, parecem confirmar-se reciprocamente". Ainda segundo ele, a hegemonia é "no sentido mais forte uma cultura, mas uma cultura que tem também de ser considerada como o domínio e subordinação vividos de determinadas classes" (WILLIAMS, 1979, p.113). Desse modo, os valores e práticas alternativos e opositores exercem pressão sobre os dominantes que, portanto, não são exclusivos. O contrário também é verdadeiro: os valores e práticas alternativos e opositores à lógica dominante são moldados por limites e pressões que vêm da hegemonia, sendo possível reconhecer a produção e a adaptação de forças alternativas na própria cultura dominante. Uma vez que o conceito de hegemonia ultrapassa a noção de dominação, "a realidade de um processo cultural deve, portanto, incluir sempre os esforços e as contribuições daqueles que estão, de uma forma ou de outra, fora, ou nas margens, em termos de uma hegemonia específica" (WILLIAMS, 1979, p.116).

Em Williams (1979), portanto, a tradição, menos que repertório e acervo, se revela uma prática dinâmica e um campo de lutas no presente, com claras implicações para os entendimentos acerca do passado e do futuro. Não é gratuito, então, que a tradição, como uma prática cultural, esteja diretamente vinculada, sob o olhar do pensador britânico, ao agir e à configuração das instituições e aos processos histórico-sociais de formação de indivíduos, grupos e realidades. É pela ação (às vezes contraditória e conflitiva) das instituições que uma tradição adquire hegemonia (podendo alcançar o caráter de cânone) e se insere num jogo ideológico de legitimidades mútuas. É, portanto, pelos processos de institucionalização que essa mesma tradição se naturaliza, que as conexões que a constituem se tornam epistemologicamente óbvias, indubitáveis, reconhecíveis.

Se explicitada dessa forma em Marxismo e Literatura, a noção de tradição seletiva aparece pela primeira vez na obra de Williams em The Long Revolution, livro de 1965. Segundo Williams, é preciso distinguir três níveis de cultura. Existe a cultura vivida de um tempo e lugar em particular, apenas totalmente acessível àqueles que vivem naquele tempo e lugar. Existe a cultura registrada (ou documentada), de todo tipo, da arte aos fatos mais cotidianos: a cultura de um período. Há, também, como o fator que conecta cultura vivida e documentada, a tradição seletiva: numa sociedade como um todo e em todas as suas atividades particulares, a tradição cultural pode ser vista como uma seleção contínua de ancestralidade.

Na análise da cultura, segundo Williams (2001), o estado existente (vivo, presente, pujante e dinâmico) da tradição seletiva é de fundamental importância, pois muitas vezes há alguma mudança nessa tradição, estabelecendo novas linhas com o passado, quebrando ou refazendo linhas existentes. Nesse sentido, a tradição não é apenas uma seleção, mas também uma interpretação. Se não é viável devolver um produto cultural ao seu período (como num processo sem a mediação da interpretação), pode-se tornar a interpretação 
consciente, uma prática de inteligibilidade sobre o passado-presente-futuro, buscando ser capaz de apontar, segundo Williams (2001), para alternativas históricas. Sendo assim, a análise da tradição busca relacionar a própria interpretação que a constitui com os valores contemporâneos particulares sobre os quais ela se baseia e explorar os padrões de seu trabalho de memória, evidenciando como e porque determinadas seleções e intepretações foram feitas.

A complexidade reflexiva no trabalho de Williams advém do entendimento da análise do que chama de "cultura vivida" (WILLIAMS, 2001, p.66) ou, mais tarde, do "processo sociocultural concreto" (WILLIAMS, 2010, p.246), que consiste em um número potencialmente infinito de práticas sociais, produtos culturais, relacionamentos, valores e documentos. O potencial infinito de práticas e valores evidentemente excede os documentos nos quais eles são registrados. Isso significa que, de um período histórico a outro, tudo o que sobreviverá ao período anterior é sua "cultura registrada" (WILLIAMS, 2001, p.66). Contudo, a própria sobrevivência da cultura registrada depende da construção de "tradições seletivas": "uma intencionalmente seletiva, uma versão de um passado modelador e presente pré-moldado", não é uma seleção neutra de períodos anteriores, mas "uma versão do passado que se destina a conectar e ratificar o presente" (WILLIAMS, 1979, p.115-116).

A consequência necessária da tradição seletiva é o que causa a rejeição de um número significativo de áreas culturais em relação às formas concretas de reconhecimento. Para apresentar este nosso, este nós aos outros, pode se servir de diferentes cenas, eventos e performances, tornando-os um lugar comum para representações de uma coletividade. A tradição seletiva é assim revelada como um caminho inevitável para se mostrar aos outros e para si mesmo, uma vez que se trata de um "processo deliberadamente seletivo e de conexão que oferece uma ratificação histórica e cultural de uma ordem contemporânea" (WILLIAMS, 1979, p.116).

Desse modo, para Williams (2001), nosso contato com o passado é então duplamente limitado: a cultura registrada (ou documentada) de qualquer período é apenas uma parte muito pequena de sua atividade humana total, mas mesmo essa parte foi radicalmente selecionada pelo efeito hegemonizante da tradição seletiva. Daí a importância política da máxima da complexidade, encapsulada em uma das passagens mais enfáticas da obra de Williams (1979, p.125): "nenhum modo de produção e, portanto, nenhuma ordem social dominante e, portanto, nenhuma cultura dominante jamais inclui ou exaure toda a prática humana, a energia humana e a intenção humana". Nenhum problema de epistemologia, nenhum excesso de problematização sobre o sistema, a complexidade de Williams é o fato sócio-ontológico de potencial infinito - e infinita multiplicidade - das práticas humanas. A ênfase de Williams na complexidade é tanto política quanto metodológica: é uma tentativa de produzir uma teoria adequada às descontinuidades e potencialidades do presente, com vistas a intervir na mudança social. 
Não é de admirar, portanto, que Williams tenha modificado a teoria da hegemonia de Gramsci, que vê "relações de dominação e subordinação como, de fato, uma saturação de todo o processo de vida" (WILLIAMS, 1979, p.111), fundindo-a com seu próprio esquema tripartite de tradição cultural: dominante, residual e emergente. Este esquema envolve uma sutura do passado, presente e futuro através de três modos de presença, de três modos nos quais o presente se apresenta. Existem heranças sociais residuais que se formaram no passado, mas que ainda estão ativas no processo cultural, e que podem oferecer alternativas para opor ou reforçar a ordem social; o dominante, que é um totalizador, mas não total, na incorporação do social como tal; e o emergente, que envolve o processo de se fazer um futuro alternativo, isto é, aquilo que o presente lega às gerações futuras, desde que escape à incorporação ao dominante.

A chave para essa complexidade temporal, segundo Williams (1979), é seu dinamismo: o dominante permanece dominante apenas à medida que incorpora constantemente o emergente. A hegemonia, para se manter como tal, busca capturar todas as relações sociais emergentes, de modo que as suas próprias regras e valores permaneçam hegemônicas. O status quo nunca é estático, mas uma operação incansável de incorporação, apropriação e apoderamento. No campo literário, por exemplo, os estilos e formas dominantes mantêm sua hegemonia apenas à medida que captam e incorporam as estruturas e práticas emergentes e alternativas. Além disso, porque as formas dominantes incorporam ou implicam certas distribuições de relações sociais favoráveis à classe dominante, elas atuam como um baluarte cultural de seu poder. A criação verdadeiramente emergente, no entanto, ocorre e é usualmente contemporânea ou sucessora iminente de outras mudanças generalizadas na formação social.

Assim, a máxima da complexidade na teoria de Williams agora pode ser resumida. Em primeiro lugar, a multiplicidade potencialmente infinita de práticas sociais, relacionamentos, valores e documentos excede todo pensamento, todos os artefatos materiais sobreviventes e todas as tradições seletivas que constituem nossa relação com o passado. Em segundo lugar, a experiência social não é (ainda) totalmente articulável; consiste de elementos padronizados, mas não falados ou não registráveis, que eludem todos os sistemas conhecidos de pensamento e expressão. Finalmente, o presente é sempre descontínuo: um campo de batalha entre relações sociais residuais, dominantes e emergentes. Todas essas três dimensões são essenciais para se construir uma análise cultural a partir de Williams e explicitam sua importância para a apreensão dos movimentos do tempo na cultura, nos quais a instabilidade da tradição, seletiva, é um componente decisivo.

\section{Tradição, tradições e tradicionalidade em Ricoeur}

O caráter ideológico da tradição é reconhecido por Paul Ricoeur quando este caracteriza o último dos três termos em que desdobra a noção. Em suas reflexões sobre os 
modos como fazemos história, sendo afetados pelo passado (e, consequentemente, abrindo horizontes e expectativas), o filósofo francês vê que sob o termo tradição estão englobadas relações muito distintas, nomeadas por ele através das expressões tradicionalidade, tradições e Tradição ${ }^{1}$. É nesta última que se encontram a busca de legitimidade, o jogo das instituições e autoridades e a pretensão à verdade caracterizadas, sob uma outra perspectiva teórica e outras chaves interpretativas por Williams. A Tradição, lembra Ricoeur (2010), nos oferece as bases para nossos pré-conceitos, para que um conjunto de prejulgamentos se estabeleça, com a autoridade do peso da história.

Esses pré-conceitos constituem uma dimensão importante do que Ricoeur chama de hermenêutica da tradição, aquela que envolve os modos interpretativos do mundo postos em cena pelos operadores de uma leitura do passado (e do presente e do futuro) que se veste de autoridade e legitimidade e cuja verdade é apresentada menos como pretensão e mais como fato. Diante do peso desse juiz, restam então "as armas de uma crítica das ideologias" (RICOEUR, 2010, p.384), que põe em perspectiva a linguagem, mas também o trabalho, a experiência e a dominação. Ricoeur nesse ponto é bastante cuidadoso ao alertar para os perigos de, num esforço de uma crítica ideológica, cair-se numa ideia de verdade transcendental e ahistórica. Assim, se "uma presunção de ideologia pesa sobre qualquer pretensão à verdade" (RICOEUR, 2010, p.384, grifos do autor), só nos cabem gestos contra-ideológicos localizados, autolimitados, na circunstância e nas fronteiras de uma dada experiência comunicativa, sob o risco de, como críticos, desconhecermos o que há de ideológico na verdade que mobilizamos para contrapor uma dada Tradição.

Recusando-se a reduzir seu significado a falso ou ilusório, Ricoeur se esforça por estender consideravelmente o âmbito da ideologia, enquadrando-a numa teoria geral da interpretação. Tanto é assim que a ideologia se refere, para ele, a todos os mecanismos simbólicos pelos quais o homem se entende em determinada cultura. Ao mesmo tempo, saindo da dicotomia entre o verdadeiro e o falso, o real e o ilusório, Ricoeur lança um desafio a toda a tradição filosófica e sociológica positivista. É porque a ciência em si, neste aspecto, não é inteiramente livre de ideologia. Tudo acontece como se fosse impossível deserdar o que é ideologia e o que é ciência, o que é ilusório e o que é real. Quando Ricoeur (1997) fala de função positiva da ideologia, ele se coloca numa perspectiva antropológica, próxima à de Clifford Geertz (1989). A ideia é pensar a ideologia como um conjunto de mediações simbólicas através das quais a realidade social e política é estruturada. O que é positivo aqui não é outro senão a necessidade de qualquer grupo recorrer a essas mediações (mitos, lendas, narrativas históricas, valores estruturantes) para construir uma identidade coletiva, para se colocar em cena, para comunicar-se um ao outro. A culpa última de Marx e marxistas, segundo ele, é reivindicar o acesso a uma realidade nua, uma práxis pura e não simbolizada. No entanto, análises antropológicas mostram

1 A tradução brasileira de Tempo e Narrativa, de 2010, opta pela grafia tradição. Preferimos aqui a usar a palavra em maiúscula, tal como ocorre na versão original em francês e na tradução em inglês, para marcar o peso da autoridade presente nessa dimensão da tradição e para diferenciar esse sentido da noção geral. 
que "a ação é imediatamente regulada por formas culturais, que fornecem matrizes e estruturas para a organização de processos sociais ou psicológicos, da mesma forma que os códigos genéticos fornecem tais estruturas para processos orgânicos" (RICOEUR, 1997, p.31). É por isso que é provavelmente ilusório querer desmascarar por trás de um sistema simbólico uma realidade que não seria: por trás de uma camada simbólica, encontramos ainda outras camadas simbólicas.

Como se vê, ainda que atento às dimensões ideológicas das pretensões de verdade da Tradição, Ricoeur permite-nos reconhecer uma preocupação de fundo, de claro sentido ético e epistemológico. O reconhecimento dos limites da crítica ideológica assim como dos movimentos da hermenêutica da tradição expõe uma questão epistemológica em torno do estabelecimento da verdade e um problema ético, no reconhecimento da verdade do outro e dos limites das nossas próprias ações interpretativas.

A base ética e epistemológica das reflexões ricoeurianas sobre a tradição, portanto, se insere no conjunto maior de suas reflexões sobre tempo e narrativa e, especialmente sobre a dialética, entre agir e padecer na história. Novamente, como Kearney sintetiza: "A tradição deve agora ser compreendida como uma dialética em curso entre a) nosso ser afetado pelo passado e b) nossas projeções imaginativas da história por fazer" (KEARNEY, 2004, p.60). É importante lembrar que, em Ricouer (2010), a noção de dialética não pressupõe um momento de síntese que subsumisse tese e antítese, sendo antes uma tensão permanente, uma configuração provisória de continuidades e descontinuidades, de identidades e diferenças, que nunca encontra solução final e que, portanto, constantemente nos afeta e nos põe em ação.

Ao longo dos três volumes de Tempo e Narrativa, a discussão da tradição surge em mais de um momento, como no volume segundo, sobre as variações imaginativas da ficção, apresentada então sob a forma da dialética de sedimentação e inovação. Como observa Kearney (2004), a dialética sedimentação/inovação é inicialmente observada no âmbito da mímesis 2 - ou seja, nos processos de configuração narrativa - para, a seguir, ser um importante elemento entre aquela e a mímesis 3, isto é, os processos de refiguração narrativa, pela ação dos sujeitos que com elas se envolvem. Sinteticamente, a sedimentação remete ao acervo de formas que alcançam, a partir do passado, um dado presente. Esse acervo é constituído por um processo de ordenamento, de acúmulo de experiências passadas, que se tornam paradigmáticas. No entanto, diz Ricoeur, a sedimentação não apaga as possibilidades de ruptura, de criatividade, de inovação. Sedimentação e inovação são interdependentes, portanto, à medida que a primeira oferece repertório e parâmetro para o trabalho propositivo e imaginativo da segunda. Nesse momento, como se vê, a tradição já se apresenta como um conjunto de relações móveis, sujeitas a contínuo trabalho de interpretação.

Mas é no encerramento do terceiro volume, num capítulo significativamente chamado de Por uma hermenêutica da consciência histórica, que a tradição adquire mais 
clareza e densidade no pensamento ricoeuriano. Nesse momento, o termo tradição é sistematizado e suas relações tripartidas em tradicionalidade, tradições e Tradição. Se este é o lugar da pretensão ideológica da verdade, as outras duas comportam relações bem distintas. Ricoeur assim sistematiza os três termos:

A tradicionalidade designa um estilo formal de encadeamento que garante a continuidade da recepção do passado; nesse sentido, designa a reciprocidade entre a eficiência da história e nosso ser-afetado-pelo-passado; 2) as tradições consistem nos conteúdos transmitidos na qualidade de portadores de sentido; situam todas as heranças recebidas na ordem do simbólico e, virtualmente, numa dimensão linguageira e textual; nesse sentido, as tradições são proposições de sentido; 3) a tradição, enquanto instância de legitimidade, designa a pretensão à verdade (o ter-por-verdadeiro) oferecida à argumentação no espaço público da discussão. (RICOUEUR, 2010, p.386-387, grifos do autor).

Novamente, o fundo ético e epistemológico se revela. Por tradicionalidade Ricoeur entende um aspecto da temporalização da história, que está vinculada à experiência, "entre a eficiência do passado, que sofremos, e a recepção do passado, que operamos" (RICOUEUR, 2010, p.374). A tradicionalidade seria assim uma espécie de consciência do atravessamento do tempo que todos nós experienciamos e que se vincula à dialética de que só podemos agir na história por sermos afetados por ela. Menos que um conteúdo, portanto, a tradicionalidade deve ser vista como um transcendental do pensamento da história, ou seja, como uma categoria sem significado específico que permite apreender, na experiência, a consciência do tempo que atravessa e conforma as realidades. A tradicionalidade, quando é inscrita numa dada experiência histórica, tem como complementos as noções de situação e horizonte.

É porque estamos numa dada situação que um certo horizonte (para o passado e para o futuro) se abre. Esse horizonte é sempre então em movimento, uma vez que emerge para cada consciência histórica quando nos posicionamos no nosso mundo. Daí decorre que nossas relações com o passado implicam a consciência de um outro (o que já foi), tomado sempre em relação ao que entendemos como presente. É por isso que a tradicionalidade emerge vinculada à fusão de horizontes.

Para Ricoeur (2010), ser-afetado-pelo-passado é uma condição que traz consigo a ideia de um trabalho, de um agir no presente que projeta, a partir de uma dada experiência, um olhar sobre a mudança, sobre os movimentos do tempo. A tradicionalidade, termo que visa alcançar a consciência desse atravessando, certamente alcança o passado, mas projeta-se também para o futuro, à medida que atribui sentido histórico para o que se passou, o que acontece e consequentemente o que virá.

Se tradicionalidade é uma categoria transcendental, ou seja, sem um conteúdo específico (mas que permite apreender as formas como o tempo é percebido numa dada 
experiência), o núcleo de sentido do termo tradição que se refere à ideia de herança cultural é coberto, segundo Ricoeur, pela expressão tradições. "A noção de tradição, tomada no sentido das tradições, significa que nunca estamos numa posição absoluta de inovadores, mas sempre, primeiro, em situação relativa de herdeiros" (RICOEUR, 2010, p.377). É fundamental observar, na sua reflexão sobre a herança cultural, pelos menos dois aspectos importantes do pensamento ricoeuriano. Primeiro, ao usar a expressão tradições, Ricouer recusa a ideia de que os produtos, os conteúdos, as obras que herdamos constituam um todo homogêneo e coerente entre si. Ao contrário, pela adoção do plural ele parece afirmar exatamente que essa herança é heterogênea e contraditória, tendo mais de uma origem no tempo e nas realidades passadas. Segundo, exatamente por ser conteúdo e heterogêneo, as tradições implicam nossa inserção, nossa atuação “...ao longo de cadeias de interpretação e de reinterpretação" (RICOEUR, 2010, p.377), ou seja, mesmo na condição de "conteúdos" herdados, a tradição implica movimento e transformação.

Como o próprio Ricoeur (2010, p.377) escreveu, a tradição no sentido de tradicionalidade significa que "a distância temporal que nos separa do passado não é uma intervalo morto, mas uma transmissão geradora de sentido. Antes de ser um depósito inerte, a tradição é uma operação que só pode ser entendida dialeticamente na troca entre o passado interpretado e o presente interpretante". Nesse sentido, "uma vez que entendemos por tradições as coisas ditas no passado e que chegaram até nós por uma cadeia de interpretações e reinterpretações, é preciso acrescentar uma dialética material dos conteúdos à dialética formal da distância temporal" (RICOEUR, 2010, p.379). Além disso, é preciso ter claro que "o passado nos interroga na medida em que o interrogamos" (RICOEUR, 2010, p.379).

Nos estudos aqui mencionados, tão diferentes entre eles, ficam evidentes alguns aspectos importantes do modo como Ricoeur (2010) pode contribuir para uma problematização comunicacional da tradição: 1) a tradição não se refere ao passado como um tempo ido, acabado ou finalizado, mas ao processo narrativo de construção de um determinado passado como referência para a organização de determinados setores, coletividades ou grupos de um presente; 2) a tradição é fundamentalmente narrativa, porque trata de um modo de compreensão e representação do passado, o que faz caber ao analista dar conta do processo de produção de sentidos sobre o passado como parte de um processo de interpretação e disputa e 3) a tradição se dá também como um processo de recepção (ou, mais precisamente, de reconhecimento), uma vez que só pode ser tradicional num determinado campo ou em relação a uma dada experiência aquilo que é tanto reconhecido como legitimado como tal; é daí que advém a autoridade da tradição, mas também as disputas e embates pelo sentido de tradicional. Afinal, para Ricoeur (1987, p.24), "tudo o que se narra acontece no tempo, desenvolve-se temporalmente; e o que se desenvolve no tempo pode ser contado." Desse modo, a interpretação é fundamental para compreender a tradição como narrativa e a comunicação como campo central nas transformações nas formas de narrativizar e dar sentido ao mundo. 


\section{Considerações finais}

Nesse breve e limitado percurso sobre os pensamentos de Wiliams e Ricoeur sobre a tradição, percebemos diferentes formas de abordar a tradição. Embora sejam pensadores tão diferentes, em ambos, a tradição, menos que fait accompli, que uma realidade dada, implica instabilidade, diferença, conflito e trabalho. Menos que algo que resiste à mudança, a tradição é ela mesma condição de movimento, uma vez que implica lutas ideológicas e demanda nos posicionarmos frente aos outros e aos modos de saber o mundo. Nessa perspectiva, a tradição se torna figura (no sentido que dá ao termo Norbert Elias, 1999) dos movimentos culturais e epistemológicos do tempo, tanto numa dimensão macro, institucional e/ou coletiva, quanto na experiência cotidiana de cada um.

Se tanto Ricoeur quanto Williams reconhecem na tradição movimento, epistemologia e ideologia, é certo que esses termos adquirem matizes bem peculiares em suas obras. Como vimos, ambos se afastam de um entendimento marxista tradicional da ideologia. Para Ricoeur, a ideologia é parte da disputa em torno da verdade e traz consigo os desafios éticos e epistemológicos de reconhecer a relatividade da verdade (de si, do outro, de sicomo-outro), sem supor nem uma verdade última nem cair na tentação de relativismos fáceis. Já Williams (1979) o faz de dentro, a partir de um referencial ele mesmo marxista e que tem na noção de hegemonia um elemento central. A hegemonia, para ele, não é uma abstração, mas o nome de um processo social ativo, a prática da sociabilidade humana. O ideológico, para Williams, é sempre o resultado da prática humana, numa dada experiência social concreta.

Ainda que, como dissemos, a tradição seja dimensão pouco explorada nas pesquisas em Comunicação, encontramos, nos últimos anos, algumas teses que se debruçaram sobre o tema, significativamente em diálogo ou com Raymond Williams ou com Paul Ricoeur, como Escobar (2017), Manna (2016), Matheus (2011), Silva (2011), Jácome (2017). Essas teses indicam, cada uma a seu modo, a partir desses autores seminais, o conflito de intepretações inerente à tradição, seja configurado em termos de hegemonia seja enfatizando como o terpor-verdadeiro de toda proposição de sentido (inclusive sobre o tradicional) diz respeito a um sistema cultural, a uma articulação entre crença e legitimidade que está imbricada por relações de poder numa experiência social concreta. Em ambos os casos, o passado que nos chega, o presente que nos abriga e o futuro que projetamos se apresentam conflitivos, em divergentes movimentos culturais, epistemológicos e éticos. Ressalta-se, a nosso ver, portanto, a pregnância da tradição como um problema de pesquisa para a Comunicação e o quanto Ricoeur e Williams fornecem bases consistentes para a apreensão de sua instabilidade e dos movimentos do tempo nela contidos. A tradição se apresenta assim - e é o ponto que defendemos - como um lugar de trabalho investigativo, interpretativo e crítico, que permite dar relevo a esses movimentos, por mais que aparentemente paralisados por hegemonias ou por pretensas verdades inquestionáveis. 
Bruno Souza Leal é professor titular do Departamento de Comunicação na UFMG e professor permanente do PPGCOM/UFMG, na linha de pesquisa "Textualidades midiáticas". É doutor em estudos literários pela UFMG.

brunosleal@gmail.com

Igor Sacramento é professor do Programa de Pós-Graduação em Comunicação e Cultura (UFRJ) e do Programa de PósGraduação em Comunicação e Informação em Saúde da Fiocruz. É doutor em Comunicação e Cultura pela UFRJ.

igor.sacramento@gmail.com

\section{Referências}

AZEVEDO, R. J. Do brega paraense ao tecnobrega: história e tradição na websérie Sampleados. Galáxia, v. 34, p. 80-92, 2017.

ELIAS, N. Introdução à Sociologia. Lisboa, Edições 70, 1999.

ESCOBAR, G. V. "Para encher os olhos": identidades e representações culturais das rainhas e princesas do clube Treze de Maio de Santa Maria no jornal A Razão (1960-1980). Tese de Doutorado em Comunicação. Santa Maria: UFSM, 2017.

GEERTZ, C. A ideologia como sistema cultural. In: Editora Guanabara Koogan, 1989. . A interpretação das culturas. Rio de Janeiro:

JÁCOME, P. Fissuras no espelho realista do jornalismo: a narratividade crítica de Barcelona. Belo Horizonte: PPGCom UFMG, 2015

KEARNEY, R. On Paul Ricoeur: The owl of Minerva. Aldershot: Ashgate, 2004.

MATHEUS, L. Comunicação, tempo, história: tecendo o cotidiano em fios jornalísticos. Rio de Janeiro: Mauad, 2011.

MANNA, N. Jornalismo e o espírito intempestivo: fantasmas na mediação jornalística da história, na história. Belo Horizonte: PPGCOM/UFMG, 2016.

RICOEUR, P. L'idéologie et l'utopie. Paris: Seuil, 1997.

. De I'interprétation. Paris: PUF, 1987.

Tempo e narrativa: 3. O tempo narrado. São Paulo: Martins Fontes, 2010.

SILVA, F. M. Convenções históricas do talk show brasileiro: de 1950 a 1990. Revista Eco-Pós, v. 16, p. 191-204, 2013.

WILLIAMS, R. Culture and Materialism: Selected Essays. London: Verso, 2010.

. Marxismo e literatura. Rio de Janeiro: Paz e Terra, 1979.

The Long Revolution. London: Penguin Books, 2001. 